\title{
inSARa: intuitive single-target (large-scale) SAR interpretation and multi-target cross-reactivity analysis
}

Sabrina Wollenhaupt ${ }^{*}$, Knut Baumann

From 9th German Conference on Chemoinformatics

Fulda, Germany. 10-12 November 2013

inSARa (intuitive networks for Structure-ActivityRelationships analysis) was primarily developed with the objective to support the medicinal chemist in tackling SAR analysis and visualization of large data sets in a more intuitive way than fingerprint-based approaches [1]. The method takes advantage of the synergic combination of the reduced graph (RG) and the maximum common substructure (MCS) concept [2].

The main feature of the inSARa concept is a hierarchical network structure of clearly-defined substructure relationships based on common pharmacophoric features. Thus, straightforward SAR interpretation is possible by interactive network navigation. When focusing on a set of active molecules at one single target, the resulting inSARa networks were shown to be valuable for various essential tasks in SAR analysis, such as the identification of activity cliffs or activity switches, bioisosteric replacements or SAR hotspots. Based on the identification of nearest neighbours in the networks, the prediction of bioactivities is also possible.

Furthermore, inSARa can be used to investigate similarities between different targets. Targets are compared based on the overlap of common pharmacophoric pattern (RG MCSs) of the corresponding inSARa networks. According to the similar property principle, similar ligands are expected to bind to similar targets [3]. Therefore, this ligand-based analysis not only revealed meaningful similarity relationships between the analysed targets but is also beneficial for the detection of potential off-target relationships and cross-reactivities. Especially when investigating targets where no structural information is available but a set of active ligands is known (e.g.

* Correspondence: s.wollenhaupt@tu-bs.de

Institut für Medizinische und Pharmazeutische Chemie, Technische Universität Braunschweig, Beethovenstr. 55, 38106 Braunschweig, Germany
GPCRs), this complementary approach can provide important knowledge for drug design.

Published: 11 March 2014

References

1. Wawer M, Peltason L, Weskamp N, Teckentrup A, Bajorath J: Structure -Activity Relationship Anatomy by Network-like Similarity Graphs and Local Structure-Activity Relationship Indices. J Med Chem 2008, 51:6075-6084.

2. Gardiner EJ, Gillet VJ, Willett P, Cosgrove DA: Representing Clusters Using a Maximum Common Edge Substructure Algorithm Applied to Reduced Graphs and Molecular Graphs. J Chem Inf Model 2007, 47:354-366.

3. Concepts and Applications of Molecular Similarity. New York: John Wiley \& Sons;Johnson MA, Maggiora GM 1990:.

doi:10.1186/1758-2946-6-S1-018

Cite this article as: Wollenhaupt and Baumann: inSARa: intuitive singletarget (large-scale) SAR interpretation and multi-target cross-reactivity analysis. Journal of Cheminformatics 2014 6(Suppl 1):018.

\section{Publish with ChemistryCentral and every scientist can read your work free of charge \\ "Open access provides opportunities to our colleagues in other parts of the globe, by allowing anyone to view the content free of charge." \\ W. Jeffery Hurst, The Hershey Company. \\ - available free of charge to the entire scientific community \\ - peer reviewed and published immediately upon acceptance \\ - cited in PubMed and archived on PubMed Central \\ - yours - you keep the copyright \\ Submit your manuscript here: \\ http://www.chemistrycentral.com/manuscript/ Chemistry Central}

